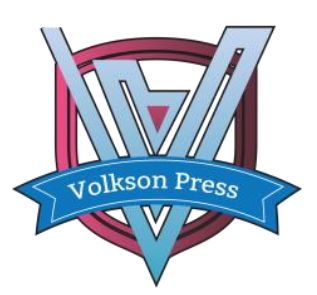

Contents List available at VOLKSON PRESS

Economics \& Management Innovations(EMI)

DOI : http://doi.org/10.26480/icemi.01.2017.36.38

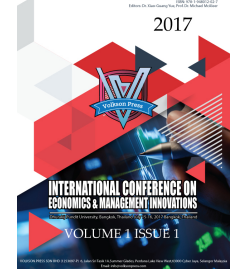

\title{
Current Development Situations and Advice of Technology Transfer and Achievement Transformation in Hubei Province
}

\section{Liu Wen1*, Wang Li1}

1 The Library of Wuhan University of Technology, Wuhan, Hubei, P. R. China, 430070

*E-mail: liuw@whut.edu.cn

This is an open access article distributed under the Creative Commons Attribution License, which permits unrestricted use, distribution, and reproduction in any medium, provided the original work is properly cited.

\section{ARTICLE DETAILS}

\section{Article History:}

Received 02 october 2017

Accepted 06 october 2017

Available online 11 october 2017

\section{Keywords:}

Technology Market, Technology

Agency, Technology Transfer, Achievement Transformation..

\section{ABSTRACT}

In order to fully implement the principle of the Third Plenary Session of the 18th Central Committee of the Communist Party of China to explore the technology market and establish the technology transfer system, this essay endeavors to explore the development trend of technology market in Hubei Province in the new era. By analyzing on the current development situations of the technology market in Hubei Province and its problems, it proposes that the government should devote more to provide guidance and support for technology transfer while the technology need to concentrate more on the construction of itself. By fully utilizing the mediation function of technical institution, it is possible to contribute to the successful transformation of science and technology originality and achievement in Hubei Province.

\section{Introduction}

The subjects, objects and medium of the technology market play as three indispensable parts of the exchange relationship in the technology market. Subjects of the technology market refer to natural person or legal person with capacity for civil conduct and capacity for civil right in the technology market including individuals, social organizations, enterprises, universities and scientific institutions. Objects of the technology market refer to technical products that could be transferred or traded in the technology market including patents, intellectual property rights, technical secrets as well as other technical achievements that could not apply for patent or fail to apply for patent. Medium of the technology market refers to agencies that provide various services for the supplier and demander of technology in the exchanging and communicating process of technology products, namely the technology agency. Technology agencies play an important role in the market economy by reasonably distributing scientific resources, integrating professional knowledge, establishing the communication channel between elements and subjects of the market and contributing to the transformation of science and technology into productivity[1]. In the process of accelerating the industrialization process of scientific achievements, the role of technology agency is indispensable.

2. Current development situations of the technology market in Hubei

2.1 Improvement of policy contributing to technology transfer and achievement transformation

In recent years, Hubei Province government has paid increasing attention to the transfer and transformation of scientific achievements by formulating a series of policies to support the transfer of technology and transformation of technology achievements in the technology market so as to pose constraints on the behavior of both sides of technology transformation. By regulating the transformation process of technology, the government has endeavored to promote the transfer of technology and transformation of achievements with various measurements.

2.2 Transaction value of technology contract exceeding 60 billion In order to fully explore the effectiveness of technology market, contribute to the transformation of technology and the cooperation between academic research and production, and accelerate the transformation from scientific advantage to economic development advantage. In Hubei, there are 19 technology contract registration centers and 170 technology contract stations that have been affirmed to take responsibility for the technology development, technology transfer, technology consulting and technology service contract of academic universities, scientific institutions, enterprises and government departments.

Figure 1 indicates the number and transaction volume of technology contracts in Hubei during 20016 to 2014. In 2014, the number of technology contract is 21.696 with the transaction sum of money reaching as many as 60.174 billion yuan, which respectively increase $45.46 \%$ and $43.63 \%$ on year-on-year basis. The average transaction volume of every technology contract is 2773.5 thousand yuan. As for the number of technology output contract in Hubei Province, it is 21,329 with the transaction sum of money reaching 57.952 billion yuan, which respectively increase $45.12 \%$ and $45.76 \%$ on year-on-year basis.

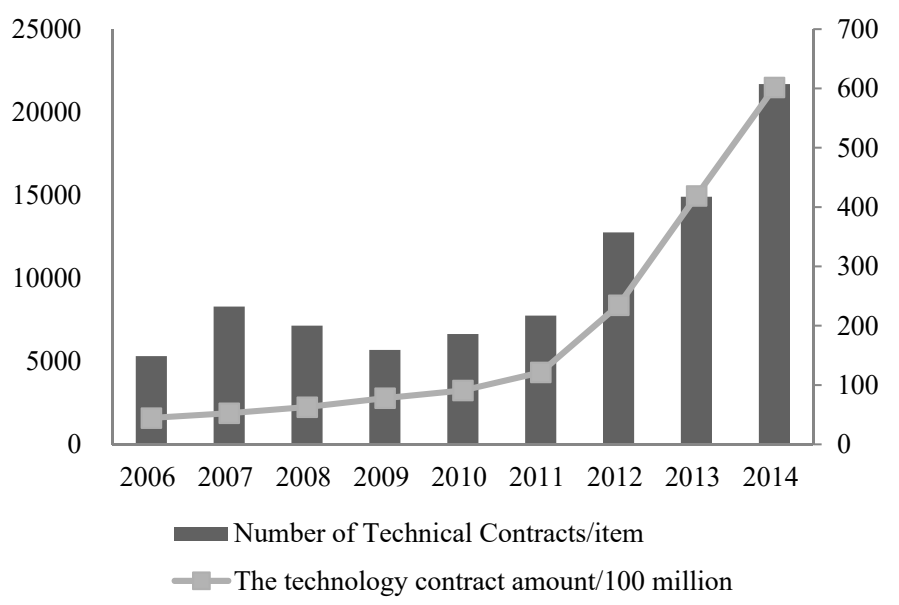

Figure 1 Turnover of Technology Contracts in Hubei and its Proportion in Midland

Source: China Statistical Yearbook of science and technology 
2.3 Rapid increase in the transaction value of technology contract of academic universities and scientific institutions

With the formulation of policies and strategies in the technology market in Hubei, the transformation of technology achievement of academic universities and scientific institutions change from the passive transformation to the market-oriented transformation. In 2014, the transaction sum of money of technology contracts of academic universities and scientific institutions reached 9.638 billion yuan, increased by 56.72 compared with 2013 , and it accounted for $16.02 \%$ of the total transaction of technology contracts in Hubei [2].

\subsection{Rapid increase in technology transaction volume in different areas}

Wuhan city has always taken the first place in Hubei in the transaction volume of technology contracts with solid economic foundation, rich science and education resources as well as the pioneer efforts made by the East Lake National Innovation Demonstration Zone. As for Yichang City, it ranked from the third place in 2013 to the second place in 2012 with the support of major project technology contracts from organizations such as the Three Gorges Project Corporation and China Gezhouba Group International Engineering Co,. Ltd. Xianning City pays more attention to the implementation of innovation policies with the combination of regional characteristic industry. Xianning also witnessed rapid increase in the volume of technology contracts in 2014 reaching 1.07 billion, which increased $254.46 \%$ on year-on-year basis. It was also the region in Hubei with the fastest increasing speed in volume of technology contracts [2]

\section{Main problems}

\subsection{Lack of qualified and comprehensive technology transformation talents with limited development potential}

The process of technology transformation and achievement transformation calls for the participation of professional talents who are capable of technology, law and marketing skills. In other countries, every professional staff is able to take responsible for the whole process of technology transformation, including evaluation on the invention, market and technology, conducting patent application with outsourced lawyers, negotiating on license agreement and conducting supervision on the operation performance of licensee[3]. One common problem in China is that most employees in technology agencies are working without professional backgrounds since that students could not gain access to courses such as technology transformation and technology evaluation in higher education in China. Even after they enter the technology transformation service industry, they could not receive systematic training and education, which leads to the lack of comprehensive and qualified technology talents and management staffs. On the other hand, owing to the lack of market-oriented standards and guidelines, the limited payment level in this industry has reduced the attractiveness of positions in the technology agencies for excellent talents. The negative circle starts from lack of talents, stagnant industry prospect to lack of talents.

\subsection{Weak public information infrastructure system with limited sharing resources}

On one hand, effective and useful information resources in single platform in Hubei are distributed. For instance, in spite of the fact that some enterprises may have established the achievement resources database while other institutions have posed the requirements on technologies, these information systems are decentralized in different scopes and ranges with loose cooperation relationship between different institutions. The lack of lateral information sharing and communication channels has resulted in the incompact relationship between enterprises, technology agencies, universities and scientific institutions, thus increasing the difficulty for the suppliers and demanders in gaining access to first-hand data and information. The lack of effective information channels and platforms would definitely pose obstacles on the transformation of technology and achievement. More useful resources may be wasted in the form of information isolated islands and large amount of repeated work in introducing technologies.

\subsection{Low level of successful achievement transformation rate}

As can be inferred from the report published by the National Development and Reform Commission in 2013, the transformation rate of technology achievement in China was 10\%, which lagged behind the rate of $40 \%$ in developed countries[4]. Hubei Province is known for the rich resources in education and scientific research, and it is characteristic of the high productivity in pure scientific research output such as papers and award results as well as low productivity in business application achievement such as patent and new products. Only a small proportion of achievement could be transformed into actual manufacturing and productivity while most of them are applied in laboratories Academic universities and scientific institutions have to deal with tough problems in the promotion and transformation of scientific achievements. Take Huazhong University of Science and Technology as an example. There are currently more than 500 pieces of scientific research achievements that have not been transformed in the National Laboratory for optoelectronics, which may go out of effectiveness as time goes by. On the other hand, the lack of market-oriented awareness may lead to the disconnection between scientific achievement in universities and market demands. It is widespread for the technology suppliers fail to establish the cooperation relationship with technology demanders, which may also account for the low successful transformation rate of achievements.

\section{Suggestion for the development of technology market in Hubei}

\subsection{Formulation of favorable policies}

First of all is the improvement in laws and regulations in relation to technology transformation. It is of great significance to establish effective guarantee mechanism, stimulation mechanism, regulation and punishment mechanism for technology transformation. Moreover, various technology and achievement transformation agencies should be encouraged to work independently with supported government to make full use of the market mechanism in the background of market economy. With the formation of development model under self management and self competitiveness, it is possible to

contribute to the development of technology agencies as the economic entity taking responsible for its own development and monitoring. Secondly is the integration and improvement in various policies and strategies to contribute to the transformation of technology. Relevant policies including Opinions of Wuhan Government on Further Accelerating Transformation of Scientific and Technological Achievements, Measures of Wuhan Municipality for the Administration of Technology Transfer Services and Technology Trade Incentive Subsidies should be attached with more importance in the implementing process. Government should also implement the assistance plan for technology transfer and transformation. As for the technology service agencies, they should develop towards the trend of operate professionally with income distributed in the shareholder form and branding corporate reputation[5]. Next is the establishment of supervision system on technology transformation. By accelerating and improving the supervision system on the technology market, it is necessary to register and count the technology contracts, standardize the statistic caliber and improve the statistical and analysis level.

\subsection{Development of professional technology agents}

According to the requirements of technology agency institutions, staffs should be equipped with professional background and concentrated fields. As a result, the training and education system for employees in technology agencies should be paid with more attention. Measurements include provide training courses according to the requirements of technology agencies, work out annual training plans and training focus to ensure the training duration time and expense. Moreover, it is also necessary to attach more attention to the development of training courses for staffs based on the demands of technology agencies, and the encouragement on various technology agencies to attract excellent talents from domestic and overseas should also not be ignored. The mutual development plan between institutions and local government for the training of talents is also an effective way of developing professional technology agents. By establishing the qualification identification and evaluation system for employees in the technology agencies, professional trainings such as economy, law, financial and security should be provided for talents to cultivate more professional agents who are familiar with academic knowledge and marketing skills.

\subsection{Construction of market-oriented operation mechanism following market discipline}

A variety of technology transfer and achievement transformation agencies and service institutions should be encouraged to work independently with government departments. By deepening and expanding the mechanism system revolution, it is possible to figure out the relationship between government executive departments and agencies of technology transfer and achievement transformation. With the accelerated separation between technology agencies and executive departments, technology agencies could transform into independent for-profit or non-profit organizations without any executive responsibility and function. For some non-profit technology agencies, corporatization operation and management model should be applied to arouse the development motivations in face with pressure from the market, thus making sure that technology agencies with various natures could take full advantage of the market mechanism in the background of market economy. When they are able to autonomously operate and compete according to their own responsibilities 
and features, these technology agencies are able to develop into economic entities with awareness of self operation, self-disciplines and self development and taking corresponding risks.

\subsection{Improvement in successful transformation rate of current scientific achievement}

First of all, both regional governments, universities and scientific research institutions should formulate detailed rules and regulations in response to the Interim Measures for the Promotion of Scientific and Technological Achievements Transformation of Universities and Scientific Research Institutes published by Hubei Province by considering the practical situations of different institutions, which may encourage more holders of scientific achievements to transform their achievements. Next is the establishment of three-dimensional evaluation system which collects value evaluations from both sides of supply and demand, professions and peers. By attaching more importance to scientific results with higher comprehensive rates, the promotion and technology transfer work would be more effective. Next is the encouragement on the cooperation between Production, Teaching and Research,

which means the encouragement on the associated projects between universities, scientific research institutions and enterprises. By providing more favorable conditions and policies for projects with joint efforts from Production, Teaching and Research, the correlation and cooperation between scientific results and enterprises' demands would be strengthened.

\section{Conclusi}

In the technology market, technology agency institutions play an important role. By far, however, the promotion effectiveness of technology agencies in Hubei on technology innovation and achievement transformation has not been fully utilized. After the Third Plenum of the 18th CPC Central Committee which has formally put forward the expectations on the activation of technology trade market, technology agencies are provided with great development opportunities and possibilities. In addition to the support and guidance from government, technology agencies should also establish the scientific operation model by seizing the valuable development opportunities. Technology agencies should also improve the internal stimulation mechanism, establish the operation and management system, improve its service capabilities to make contribution to the development and expansion of technology market in Hubei Province.

\section{Acknowledgement}

This work was supported by the Universities of Hubei Province Work Committee for the 2016 Research Fund (Grant No.: 2016-ZJZD-02)

\section{Bibliography}

Liu Wen (1983-), female, postgraduate of 2008 from Wuhan University of Technology, School of Materials Science and Engineering, now works in the library of Wuhan University of Technology, novelty search station.

Corresponding author: Wang Li (1982-), female, postgraduate of 2008 from Wuhan University of Technology, School of Automation, now works in the library of Wuhan University of Technology, novelty search station.

\section{References}

[1] Wen Yuedong. Development features and inspirations of technology agencies in developed countries [J]. High-Technology and Industrialization. Vol. 10 (2003), p. 42-44.

[2] Science and Technology Department of Hubei Province, Association of Technology Market of Hubei Province. Report on the registration, statistic and analysis of technology contracts in Hubei Province 2014 [R]. Wuhan, 2015.

[3] Cao Yang, Chen Shijun, Wang Xueping. Function position of scientific agencies in the national innovation system and its operation mechanism $[\mathrm{J}]$. Scientific Policies and Management. Vol. 4 (2007), p. 20-24.

[4] Chen Xiaolie. Scientific achievement transformation rate of National Development and Reform Commission reaches only $10 \%[\mathrm{~N}]$. China Construction, 2013-12-26 (8).

[5] Science and Technology Department of Hubei Province. Forum held by Science and Technology Department of Hubei Province on accelerating the construction of technology transformation agencies and promoting the transformation of scientific achievement [EB/OL].(2014-04-17). http:// www.hbstd.gov.cn/mbjj/32993.htm. 